International Journal of Advanced Academic Research | Sciences, Technology and Engineering | ISSN: 2488-9849

Vol. 6, Issue 5 (May 2020)

Journal DOI: 10.46654/ij.24889849 | Article DOI: 10.46654/ij.24889849.e6528

\title{
CURBING COVID-19 PREVALENCE AND OTHER COMMUNICABLE DISEASES: THE LAXITY OF NON-LOCAL-EVIDENCE-BASED AWARENESS CREATION
}

\author{
Odji Ebenezer \\ Industrial Design Department \\ Federal University of Technology, Akure, Nigeria \\ Email: ezerodjimin@gmail.com
}

\begin{abstract}
Designing safety strategies in times of a pandemic such as COVID-19 is the responsibility of all professionals and researchers, designers inclusive. One of the effective ways to curb the prevalence of a communicable disease (CD) is through effective awareness creation (AC) to shape the attitude/behaviour of the target audiences in ways that promote public health safety. Notably, the attitude of a significant number of Nigerians towards the curbing the prevalence of COVID-19 (as at the time of this study) have been most discouraging to law enforcement officers, the government and, most importantly, health workers manning the frontlines in the fight against COVID-19 and other CDs like Laser fever. Therefore, adopting a quantitative approach of the survey type and a sample size of 385 (purposive sampling), this study revealed that the current AC strategies of entities concerned were communicatively effective. However, this effectiveness was not translating into desirable behavioural adjustments suitable for curbing the prevailing $C D$ and protecting public health. This situation was ascribed to the lack of local visual evidences of confirmed case, an omission that turned out to be the key laxity of the adopted AC strategies in the fight against COVID-19 in the study area. The study therefore recommended the use of identity-shielded visual evidences of local laboratory confirmed cases of the prevailing CDs in the production of AC campaign contents.
\end{abstract}

Keywords: Awareness Creation (AC), Covid-19, Communicable Diseases (CD), Public Health, Design. 


\subsection{Introduction}

Communicable Diseases (CD) have constituted several of the greatest challenges the world had had to deal with in the past and they, at present, still constitute major challenges for humanity's safety (Odji, 2020). For example, an estimated one-third of the world's total human population suffered from influenza between 1918 and 1919 with about 100 million fatalities recorded ${ }^{1}$, the majority of whom were youths (25-34 years) in their prime (Kolata, 2000; Gewald, 2007) resulting in significant population crashes (Ross, 2008) and crashing the economic life in many countries (Brainerd \& Siegler, 2003; Garrett, 2007). Nigeria, and indeed Africa at large, was not exempted. The influenza pandemic infiltrated Nigeria through the ports by passengers and crew members who arrived via ship from abroad rendering 50-80\% of total population stricken by the disease (Ohadike, 1991). Over $2.7 \%$ of the total population (roughly 18 million as at then) died within six months (Ohadike, 1991).

Hardly did the world expect dreaded history to repeat itself so soon when the Coronavirus disease (Covid-19), previously designated 2019-novel coronavirus (2019-nCoV), surfaced in Wuhan, China, in December 2019 from where it spread to other parts of the world including Nigeria (Ohia, Bakarey, \& Ahmad, 2020; Odji, 2020), although such modern day pandemics have been projected/insinuated in previous reports (e.g. Garrett, 2007). The 1918 influenza shared some characteristics with the Covid-19 pandemic in entry into Nigeria, in diffusion and in containment measures. The first confirmed case of Covid-19 in Nigeria was announced on January 28, 2020 (Adepoju, 2020) after which, despite the time the nation's health sector had to prepare, the rate of infection became exponential. This could be attributed, as cited in a previous study, to the nation's close trade ties with China and, most importantly, the fragility and prevailing unsustainability of its medical services (Ohia, Bakarey, \& Ahmad, 2020).

Nigeria's approach included containment measures (e.g. enforcement of containment guidelines by relevant agencies and special task forces, contact tracing and screening, which, unfortunately, were largely limited to international travellers and symptomatic carriers leaving out asymptomatic, convalescence and incubatory carriers), risk management (e.g. risk communication monitoring i.e. on social media (Adepoju, 2020)) and preventive measures (such as awareness creation (AC) and enforcement of preventive guidelines such as 'stay at home' executive orders) and so on. The most effective measures adopted during such emergencies depends much on the most vibrant causative or diffusion factor promoting the prevalence of the disease three of which, in a previous study, aside from other known dynamics, have been summed up as "ignorance, false knowledge and carelessness/carefreeness [IFC]" (Odji, 2020). According to this same study, these causative factors may be appreciably contained adopting effective AC, aside from other recommendations. However, from 323 confirmed cases and 10

\footnotetext{
${ }^{1}$ This figure is debated by some scholars as less or more.
} 
deaths recorded in Nigeria as at 13th of April 2020, the death toll rose to 221 with 7,261 laboratory confirmed cases nationwide by May 23, 2020 (NCDC, 2020). At an estimated growth rate of \pm 0.0766775 derived from using Equ. 1, it can be estimated, with possible appeal to the fallibilism ${ }^{2}$ principle (Hetherington, n.d.), that if the growth in number (as derived based on currently available $C D$ diffusion statistics) of laboratory confirmed cases in Nigeria, proceed unaltered as indicated below, considerably more than half the entire population of Nigeria would be Covid-19 affected by the end of the year.

$$
\boldsymbol{y}(\boldsymbol{t})=\boldsymbol{a}_{-} \boldsymbol{e}^{\boldsymbol{k} t} \ldots \text { Equ.1 (Maloney, 2018) }
$$

Where

$\mathrm{a}=$ Initial number of confirmed cases

$\mathrm{e}=$ exponential $\approx 2.7183$

$\mathrm{k}=$ rate of increase in number of cases (rate of growth)

$\mathrm{t}=$ time of growth/increase (measured in days)

$y(t)=$ number of cases at a given time (day) $t$.

Between 13th of April 2020 and May 23, 2020 were 40 days. Therefore, at $\mathrm{t}=40$ days, $\mathrm{a}=323$ and $y(t)=7,261-323=6938$ confirmed cases, $\mathrm{k}=0.0767$. While this estimation puts into consideration the possible gross unreliability of exponential population growth (increase or decay) (Mathews, Brown, Evans, \& Hunt, 2013), it however, serves as a pointer to a possible nationwide health disaster, such as was reported in Brazil where the number of cases doubled every 2 weeks as at 25 May 2020 (Rourke \& Agencies, 2020), that may be avertable if appropriate measures are taken in due time. One of such measures is effective AC (Odji, 2020) which, in Nigeria, had been more of statistics based than visual evidence based.

Aside from concerns posed by more intrinsic factors such as the virulence of the coronavirus and other related CDs, the best way to combat any pandemic wave is to effectively mitigate the factors promoting its prevalence in any region. Odji (2020) identified IFC as major factors promoting $\mathrm{CD}$ prevalence in rural Nigeria [Over $50 \%$ of Nigerians live in rural areas (World Bank Group, 2018)] and suggested that they could be reasonably contained through AC. Making the community sufficiently conscious of a problem is vital in creating an atmosphere where change is possible (Christiano \& Neimand, 2017). Obviously, the Nigerian Government, at both federal and state levels, and the private sector, have been investing a lot in AC even before the disease reached Nigeria. However, the prevailing attitude of the citizenry, the current diffusion rate and prevalence of the diseaseas at the time of publication (Figure 1) raises questions about the findings and recommendations of such aforementioned studies. For instance, despite the worldwide prevalence of COVID-19 and other local public health concerns such as Ebola and Lassa fever, some residents still regarded the existence of such diseases or causative pathogens

\footnotetext{
${ }^{2}$ Fallibilism is a philosophical principle which maintains that our scientific knowledge claims are unvaryingly susceptible and possesses possibilities to be falsein part or in entirety (Rescher, 1998).
} 
as untrue further spurring the exponential increase of CD cases in Nigeria and frustrating the efforts of the government, law enforcement agents and health workers in the struggle to contain the spread of the prevailing pandemic.

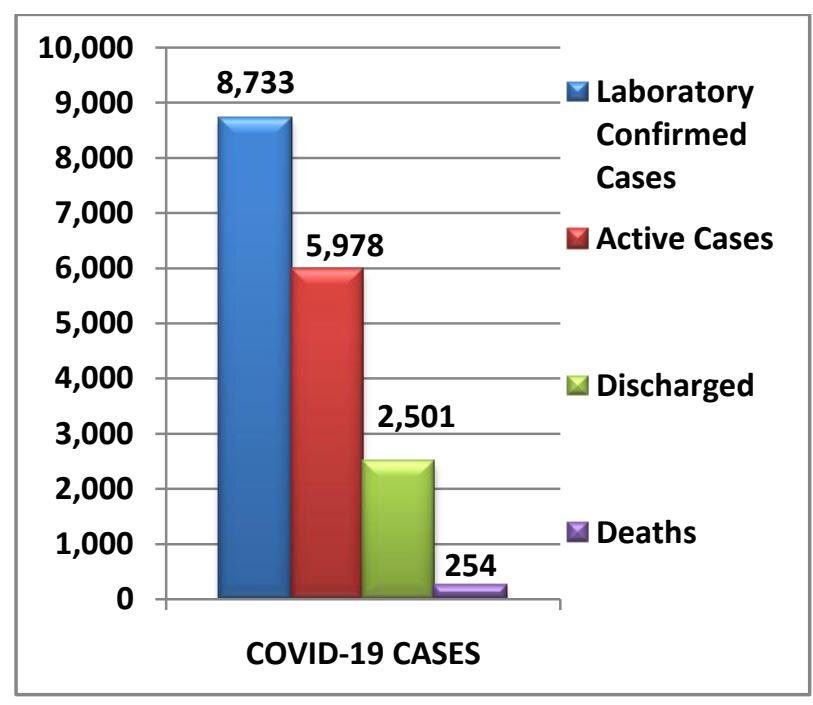

Figure 1: COVID-19 prevalence statistics as at 29 May, 2020 (NCDC, 2020).

On the other hand, if the findings and CD-mitigating recommendations of such studies were correct and applicable in public health and design, the questions then were: why were the current AC strategies not producing desirable results? What adjustments could be made to enhance the effectiveness of currently adopted AC strategies? This study attempted to unravel why the attitude of the citizenry, summarized in the acronym IFC, was yet prevalent despite the current AC efforts of the government and private sector interventions. This study was aimed at decrypting the prevailing attitude of the target audience of the current COVID-19 AC campaigns and revealing their laxities in a bid to deciphering a more effective method of influencing their behaviour for the purpose of public health safety.

\subsection{Effectiveness Assessment and AC Goals}

There are various methods that can be adopted in assessing the effectiveness of any AC campaign including communication effectiveness and goal achievement assessment. These may be achieved through the adoption of appropriate assessment metrics which may include but not limited to: the volume of mentions (online), intensity of public sentiment, online and offline media reach (Marta, 2019), engagement e.g. with interactive persuasive systems, volume of sales and so on. The method adopted depends on the goal of the AC campaign which may range from public acceptance i.e. of an idea, brand or a message, content or brand recall and so on to a target behaviour/action or attitude change and so on. However, according to a previous study, an AC campaign may yield public acceptance (i.e. desirable reach and recall), but such public acceptance may not necessarily translate into action or targeted behavioural adjustments 
(Fraustino \& Ma, 2015). This may mean the audience is entertained or educated, but not changed/influenced. Therefore, this study adopted recall and action metrics for measuring the effectiveness of the prevailing AC strategies in the study area.

\subsection{Method}

The study adopted a quantitative approach of the survey type. It attempted to reveal why the negative attitude of the citizenry in the study area, summarized in the acronym IFC, was yet prevalent despite the current AC efforts of the government. The study was limited to Akure, the capital of Ondo State, due to the lockdown restrictions put in place by the Government (as at the time of the study) to contain the spread of COVID-19. The Cochran formula (Equ. 2) was used to obtain the sample size of respondents. Criterion sampling method was adopted due to the nature of the study. The criteria for the selection of study participants included: being a breaker of one or more COVID-19 prevention guidelines and willingness to participate in the study.

$$
\boldsymbol{n}_{\boldsymbol{o}}=\frac{\boldsymbol{Z}^{2} \boldsymbol{p q}}{\boldsymbol{e}^{\mathbf{2}}} \text { (Equ. 2) }
$$

Where e (desired level of precision or margin of error) $=0.05, \mathrm{p}$ (estimated proportion of the population) $=0.5$, at a $95 \%$ confidence level giving $\mathrm{z}$ (obtained from a $\mathrm{z}$-table) $=1.96$ and $\mathrm{q}=1-$ $\mathrm{p}=0.5$. Sample size obtained $=385$. Although contestable, the population of Akure had been estimated as 420,594 (World Population Review, 2020). The sample size obtained was not reduced to improve the integrity of the results obtainable. Therefore, 385 respondents were sampled in the course of the study.

\subsection{Research Questions}

The following research questions guided the study:

\section{How much do you know about COVID-19?}

Question 1 was further broken down thus:

a) Do you know about COVID-19? [2 points]

b) Can you mention at least three ways it spreads? [6 points]

c) Can you mention at least three things to do so as to prevent contracting the disease? [6 points]

Respondents were then rated for analysis on a scale of 1-14 as shown below:

a) False knowledge $=0$ point

b) No knowledge $=1$ point

c) Minimal knowledge $=2-6$ points

d) Average knowledge $=7$ - 10 points

e) Sufficient knowledge $=11-14$ points 
Total points obtainable by a respondent $=14$. Grand total point obtainable by all respondents $=$ $14(385)=5390$ points.

\section{Why do you not keep to the (promoted) COVID-19 preventive guidelines?}

Common themes were derived from data collected on question 2 and coded accordingly.

\subsection{Research Objectives}

The specific objectives of the study were to:

1. investigate the level of knowledge of preventive guidelines defaulters as a means of assessing the communicative effectiveness of current AC strategies.

2. reveal reasons why the current $\mathrm{AC}$ strategies were not effective enough in terms of action/adjustment/behavioural adjustment.

\subsection{Data Collection and Analysis}

Data for the study were collected with the aid of a questionnaire. Interviews (asking the same questions as recorded in the questionnaire) were adopted in cases involving respondents with low educational abilities or reading challenges. As the need arose, both methods were simultaneously applied. Collected data were analysed using descriptive statistics including frequencies and percentages.

\subsection{Result and Analysis}

Table 1: Demographic statistics of respondents

\begin{tabular}{|c|c|c|c|}
\hline $\mathbf{S} / \mathbf{N}$ & Variable & Frequency & Percentage (\%) \\
\hline 1. & $\begin{array}{l}\text { Men } \\
\text { (Adult) }\end{array}$ & 133 & 34.5 \\
\hline 2. & $\begin{array}{l}\text { Women } \\
\text { (Adult) }\end{array}$ & 167 & 43.4 \\
\hline 3 & Children & 85 & 22.1 \\
\hline Total & & 385 & $100 \%$ \\
\hline
\end{tabular}

$34.5 \%$ of the respondents were adult males. $43.3 \%$ were adult females while only $22.1 \%$ of the respondents were middle-aged children. All respondents sampled were defaulters of one or more COVID-19 preventive or containment guidelines as recommended by the Nigeria Centre for Disease Control (NCDC, 2020), the Centres for Disease Control and Prevention (CDC, 2020) and as directed by the state and/or Federal Government of Nigeria with reference to Odji (2020). 


\subsection{Objective One}

The level of knowledge of respondents about COVID-19 preventive/containment guidelines was investigated. Each respondent was ranked based on total points scored and placed in appropriate categories ranging from false knowledge to sufficient knowledge. The results are as summarised in Table 2 and Figure 2.

Table 2: Knowledge levels of the respondents about COVID-19.

\begin{tabular}{lllll}
\hline S/N & Knowledge Levels & Frequency & Percentage (\%) & Rank Order
\end{tabular}

\begin{tabular}{lllll}
\hline $\mathbf{1}$ & False knowledge & 75 & 19.48 & 3rd \\
$\mathbf{2}$ & No knowledge & 7 & 1.82 & $\mathbf{5 t h}$ \\
$\mathbf{3}$ & Minimal knowledge & 61 & 15.84 & $\mathbf{4 t h}$ \\
$\mathbf{4}$ & Average knowledge & 151 & 39.22 & $\mathbf{1 s t}$ \\
$\mathbf{5}$ & Sufficient knowledge & 91 & 23.64 & $\mathbf{2 n d}$ \\
$\mathbf{T}$ & $\mathbf{T O T A L}$ & $\mathbf{3 8 5}$ & $\mathbf{1 0 0}$ & \\
\hline
\end{tabular}

Source: Odji Ebenezer (2020).

As indicated in Table 2, 23.64\% of the respondents had sufficient knowledge of COVID-19. $15.84 \%$ had minimal knowledge of the pandemic. Only $1.82 \%$ had no knowledge of COVID-19 ranking last in 5th position. $19.48 \%$ of the respondent had false or wrong knowledge of the disease ranking 2nd. A higher number of the respondents (39.22\%) had average knowledge of COVID-19 ranking in 1st place. $62.86 \%$ of the respondents had at least average knowledge of the preventive/containment guidelines while only a combined $21.3 \%$ of them had no or false knowledge about the disease. A more detailed analysis of respondents' level of knowledge was as recorded in Figure 2. 


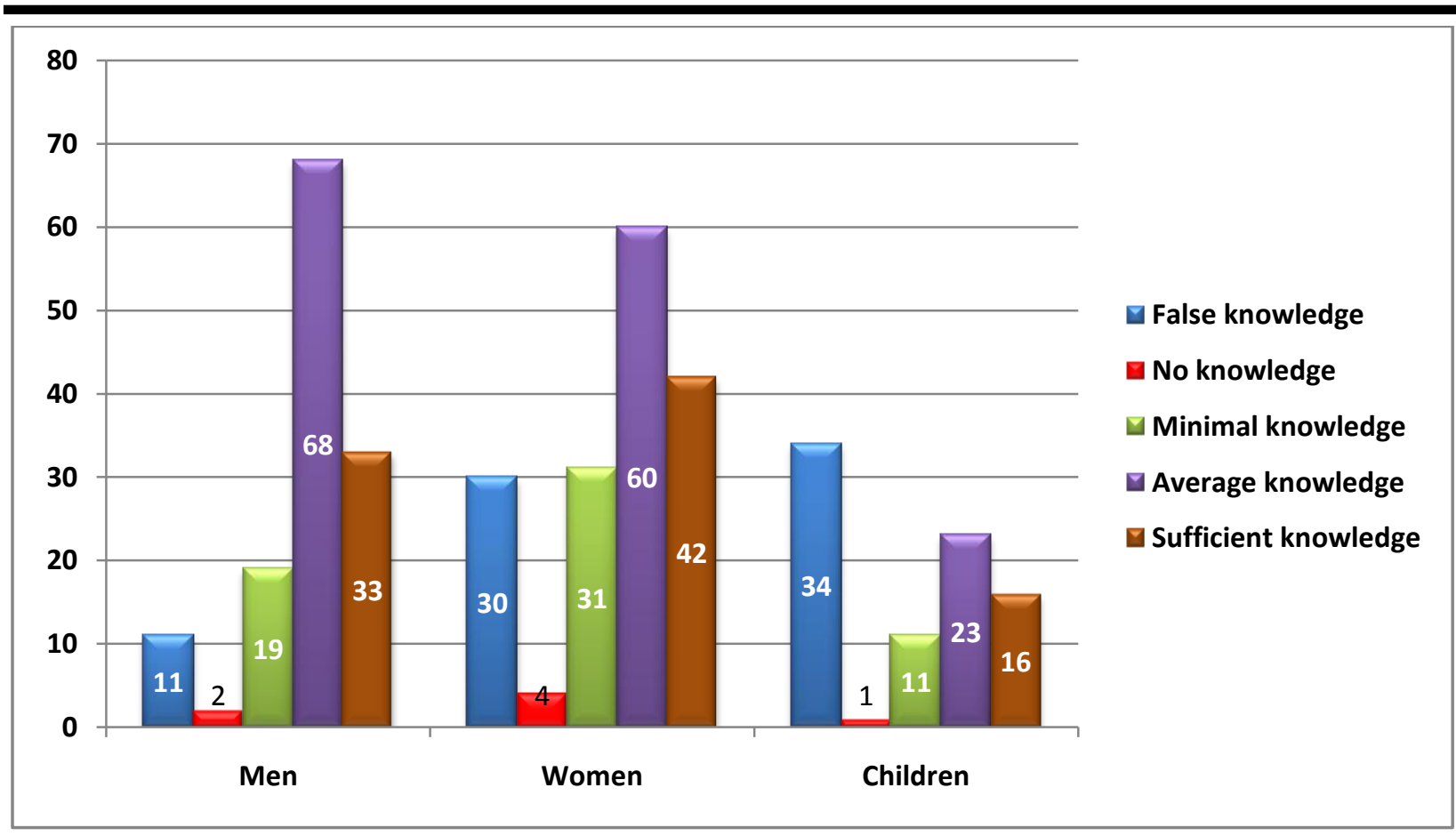

Figure 2: Detailed knowledge levels of respondents.

Source: Odji Ebenezer (2020).

As recorded in Figure 2, $14.67 \%$ of respondents that had false knowledge were men while $40 \%$ and $45.33 \%$ were women and children respectively. The highest percentage of those who had no knowledge of COVID-19 was women (57.14\%) while $28.57 \%$ were men and $14.29 \%$ were children. $31.15 \%$ of those with minimal knowledge were men while $18.03 \%$ and $50.82 \%$ were children and women respectively. Men made up the highest percentage of respondents with average knowledge of the coronavirus (45.03\%) while $15.23 \%$ and $39.74 \%$ of them were children and women respectively. $46.15 \%$ of those with sufficient knowledge of COVID-19 were women while $36.26 \%$ and $17.58 \%$ were men and children respectively.

\subsection{Objective Two}

The reasons why the current AC strategies were not effective enough in terms of action/adjustment or behavioural adjustments were investigated. Respondents were asked to indicate why they were not partly or fully adhering to the COVID-19 prevention or containment guidelines as communicated to them. Responses of the respondents to research question 2 were analysed for the achievement of this study objective. The key themes derived from the responses were coded as shown Table 3. 
Table 3: Notable themes derived from respondents' responses

\begin{tabular}{lll}
\hline S/N & Notable Themes & $\begin{array}{l}\text { Code } \\
\text { Assigned }\end{array}$ \\
\hline $\mathbf{1 .}$ & Coronavirus does not exist (in Nigeria) & CDE \\
$\mathbf{2 .}$ & $\begin{array}{l}\text { Public deception attempts (COVID-19 news in Nigeria are government lies). } \\
\text { 3. }\end{array}$ & PDA \\
& $\begin{array}{l}\text { Nigeria local vall they show us are foreign images). } \\
\text { 4. }\end{array}$ & $\begin{array}{l}\text { Economic reasons (i.e. need to earn a living as Government's palliative } \\
\text { measures are insufficient, etc.). }\end{array}$ \\
5. & Others. & ERS \\
\hline
\end{tabular}

Source: Odji Ebenezer (2020).

The number of times a theme occurred in a response was recorded as shown in Figure 3. There were cases in which response bore more than one notable theme. A total frequency of 828 was recorded. ERS and LVE were most prominent.

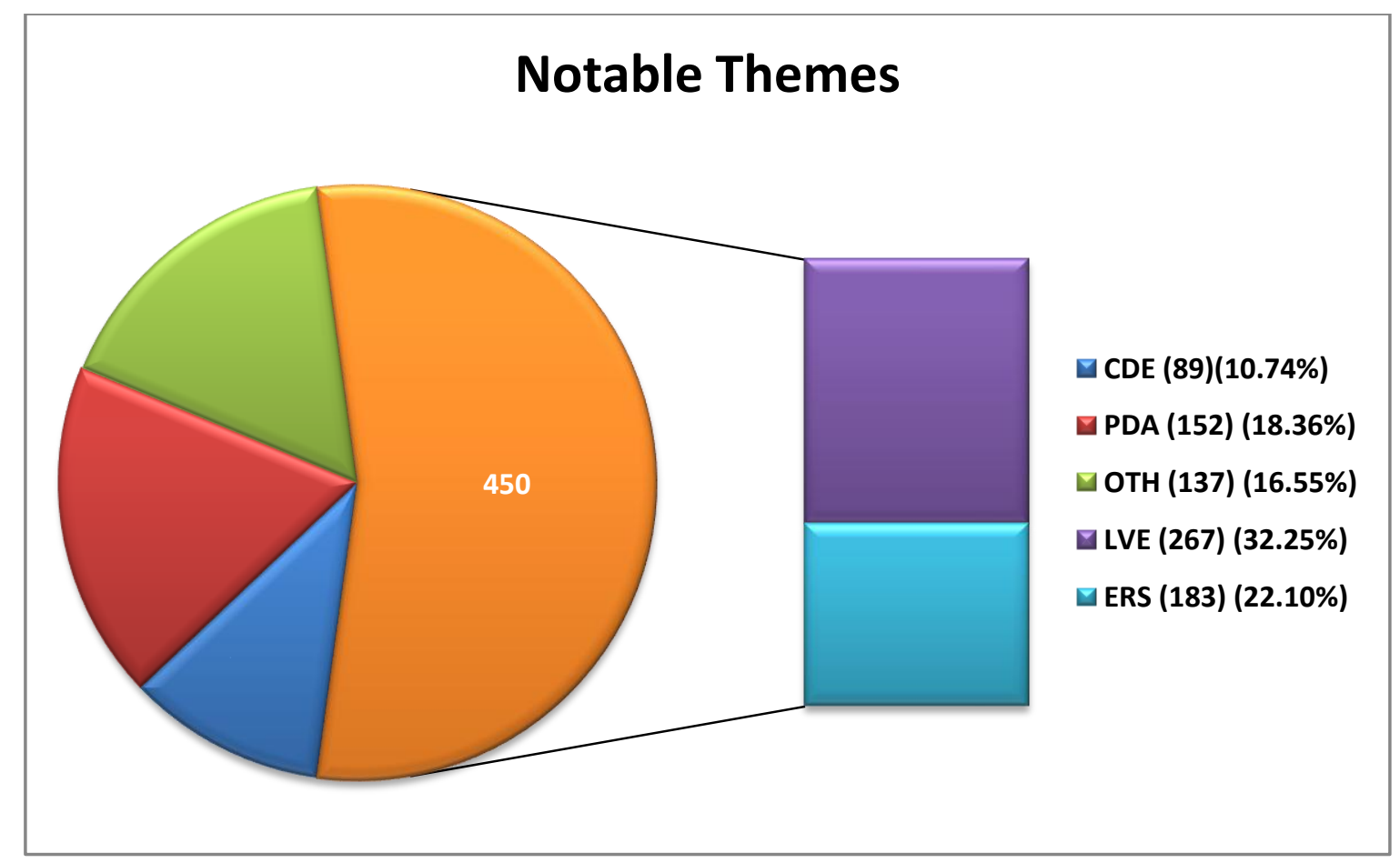

Figure 3: Notable themes describing why respondents were defaulting in keeping the COVID-19 and other CD prevention guidelines.

Source: Odji Ebenezer (2020).

From Figure 3, CDE featured 89 times (10.74\%) to rank lowest on the list. This was followed closely by OTH at 137 (16.55\%). PDA ranked third at 152 (18.36\%). ERS ranked second 
occurring 183 times (22.10\%). LVE ranked as the most influential and most frequent theme at $267(32.25 \%)$.

\subsection{Discussion}

It is unfeasible to correctly and effectively practice what you do not have (correct) knowledge about. One can only obey guidelines of which one is appropriately aware or knowledgeable. However, results presented in this study indicated that the majority of the respondents $(62.86 \%)$ in the study area had knowledge about COVID-19 averagely sufficient enough to help alleviate its current diffusion rate of the killer virus. Only an ignorable percentage had no knowledge about the disease. This meant that the current AC strategies being implemented by both the private sector and the state and federal governments are effective communication wise. The high percentage knowledge level relative to the very low level of no knowledge indicated a strong communication effectiveness of the current awareness campaigns. However, the fact that all those sampled were defaulters meant that people in the study area had averagely sufficient knowledge of the disease, but the knowledge were not translating into effective behavioural/attitudinal change or adjustments profitable for the alleviation or the containment of the COVID-19 pandemic. The question then was 'why'? The study attempted to answer this query in objective two.

Another notable observation from Table 2 and Figure 2 was that mere ignorance (having no knowledge) of the disease was arguably a problem in the study area relative to false knowledge. The existence of a high level (19.48\%) of false knowledge (having wrong knowledge) of the disease, especially amongst children and women (making up $45.3 \%$ and $40 \%$ respectively of the respondents with false knowledge), posed even greater threat as false knowledge not only amounts to error but also leads to erroneous purposive activities which may be detrimental to public health and in various other ways. There are various studies/arguments affirming the possibilities of false knowledge (Worsnip, 2015). This, it has been argued, is worse than ignorance. Standardly, it is understandably assumed that ignorance is preferable to error (Elgin, n.d.); although neither is profitable. False or incomplete knowledge is always more dangerous than ignorance (Little \& Brown, 1839). For example, some residents were observed to have been consuming high dosage of alcohol (ethanol) due to the popular false knowledge that alcohol cures or prevents the coronavirus disease when consumed regularly. This purposive act (alcohol consumption), stemming from the false knowledge of respondents, had been described as a risky behaviour which had both long and short term damaging effects on the human health, weakening the immune system (thus reducing the body's capacity to cope with CDs including COVID-19), causing cancer related illnesses, interfering with thoughts, proper judgement, decision-making process and behavioural maladjustment (WHO, 2020). Ethanol consumption had also been linked to one of the most severe complications of COVID-19: acute respiratory distress syndrome (WHO, 2020). 
Findings of this study (Figure 3) also indicated that the communicative effectiveness of an AC does not necessarily translate into behavioural/attitudinal change/influence. Even when respondents had required knowledge, the imparted/acquired knowledge did not produce a corresponding attitudinal adjustment; which meant that although knowledge increased, the ultimate goal (attitudinal/behavioural adjustment) of the AC was not considerably achieved. This trend was attributed to few factors the most prominent of which were economic pressures (ERS) and lack of local visual evidence (LVE) of the prevailing CD. Respondents based their stance on the argument that, besides the fact that they had to survive economically, all they saw or were shown were foreign images of COVID-19 victims. This suggested that in the absence of local visual evidences (motion and still images), there is a tendency for the target audience to disbelief, disregard or take lightly the persuasive messages in an AC campaign. This notion, this study revealed, was the main laxity of the current AC campaigns in the fight against COVID-19 in the study area.

\subsection{Summary of Findings}

The following were the summary of the findings of the study:

1. The current AC strategies of the governments, NGOs and the private sectors were communicatively effective.

2. However, the communicatively effectiveness of the adopted AC campaigns were not translating into sufficient desirable behavioural adjustments suitable for curbing the prevailing $\mathrm{CD}$ and protecting public health.

3. The current AC campaign contents were not being substantiated by local visual (confirmed case) evidences, an omission that turned out to be the key laxity of the adopted AC strategies in the fight against COVID-19 in the study area.

\subsection{Recommendation}

Based on the findings presented above, the following recommendations were proposed:

1. Conduct and sponsorship of timely formative or exploratory researches or campaign effectiveness evaluations. These types of research are conducted before an AC campaign is designed and executed, or while the campaign is on-going, helping to shape the contents of the persuasive messages so as to ensure its relevance to the target group, and to select the proper way to communicate the same (Masiuliené, Looney, Aertgeerts, \& Greef, n.d.).

2. Use of visual evidences of local laboratory confirmed cases of the prevailing CDs in the production of AC campaign contents.

3. Use of identity shielded images (e.g. Figure 4). Images of local confirmed cases, with identity consciously shielded to protect the right to privacy of the patient and his/her family or any other persons or entity concerned, may be adopted for content creation so as to optimise content/message credibility, acceptability and integrity of truth. Mere display of 
statistics as shown in Figure 1 may not sway the target audience to behave in expected ways, effect the intended attitudinal change or carry out the targeted actions.

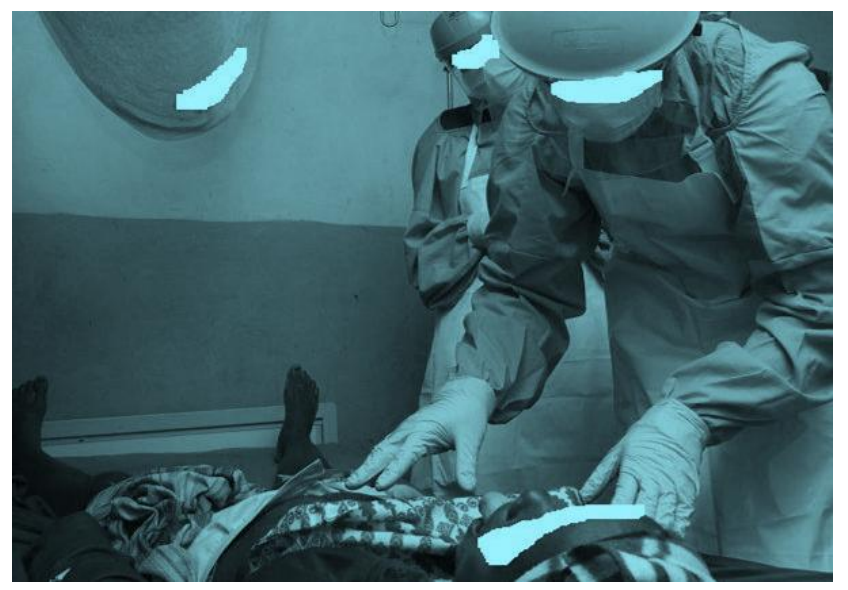

Figure 4. An example of an identity shielded image showing a patient.

Original Photo Source: Chioma (2020).

4. More intrinsic studies may be conducted on how to further improve AC content persuasiveness.

\subsection{Conclusion}

Indeed, according to the findings of this study, an AC campaign may be communicatively effective but lax in behavioural influence; meaning that the knowledge of the target audience may be increased whiles their actions/attitude or behaviour may remain uninfluenced by the same knowledge. Therefore, to achieve greater effectiveness in terms of awareness creation in the fight against CD prevalence in any region, it is needful to adopt more visual evidences of locally confirmed cases in the persuasive designs and other contents used in AC campaigns. 


\section{Reference}

Adepoju, P. (2020, MARCH 11). Nigeria responds to COVID-19; first case detected in sub-Saharan Africa. Nature Medicine (News Feature), 26, 444-448.

Brainerd, E., \& Siegler, M. V. (2003, February). The Economic Effects of the 1918 Influenza Epidemic. Discussion Paper No. 3791, p. Centre for Economic Policy Research (INTERNATIONAL MACROECONOMICS). https://cepr.org/sites/default/files/news/FreeDP_20March.pdf.

CDC. (2020, April 24). How to Protect Yourself \& Others. (Centers for Disease Control and Prevention (CDC)) Retrieved May 26, 2020, from .cdc.gov: https://www.cdc.gov/coronavirus/2019ncov/prevent-getting-sick/prevention.html

Chioma, E. (2020, April 18). 17 people dead, as Nigeria records new 51 cases of COVID-19. (Kemi Filani News) Retrieved May 27, 2020, from kemifilani.ng: https://www.kemifilani.ng/2020/04/17-people-dead-as-nigeria-records-new-51-cases-of-covid19.html

Christiano, A., \& Neimand, A. (2017, Spring). Stop Raising Awareness Already (Essentials of Social Innovation). (Stanford University, Producer, \& Stanford Social Innovation Review) Retrieved May 27, 2020, from ssir.org: https://ssir.org/articles/entry/stop_raising_awareness_already

Elgin, C. Z. (n.d.). Ignorance, Error, and the Advancement of Understanding. Retrieved May 27, 2020, from elgin.harvard.edu: http://elgin.harvard.edu/undg/error.pdf

Fraustino, J., \& Ma, L. (2015). CDC's Use of Social Media and Humor in a Risk Campaign'Preparedness 101: Zombie Apocalypse,'. Journal of Applied Communication Research, 43(2), 222-241.

Garrett, T. A. (2007). Economic Effects of the 1918 Influenza Pandemic Implications for a Modern-day Pandemic. Federal Reserve Bank of St. Louis. November (2007). Available from: https://www.stlouisfed.org/ /media/files/pdfs/community-development/researchreports/pandemic_flu_report.pdf [As at 23/5/2020].

Gewald, J.-B. (2007). Spanish influenza in Africa: Some comments regarding source material and future research. Leiden, The Netherlands. ASC Working Paper 77 : African Studies Centre. Available from: https://core.ac.uk/download/pdf/15600594.pdf.

Hetherington, S. (n.d.). Fallibilism. (Internet Encyclopedia of Philosophy (IEP) and its Authors) Retrieved May 27, 2020, from iep.utm.edu: https://www.iep.utm.edu/fallibil/

Kolata, G. (2000). Flu: The story of the Great Influenza Pandemic of 1918 and the Search for the Virus That Caused it. New York.

Little, C. C., \& Brown, J. (1839). Civil and Criminal Laws of Modern States by L. S. C. In The American Jurist and Law Magazine (Vols. 21, April, p. 69). Boston, Massachusetts. 
Maloney, L. (2018, August 24). How to Calculate Exponential Growth. (Leaf Group Ltd. / Leaf Group Media) Retrieved May 24, 2020, from Sciencing: https://sciencing.com/calculate-exponentialgrowth-8143625.html

Marta. (2019, July 31). How to measure the results of a brand awareness campaign? (Brand24, Producer) Retrieved May 27, 2020, from brand24.com: https://brand24.com/blog/how-to-measure-theresults-of-brand-awareness-campaign/

Masiulienè, L., Looney, J., Aertgeerts, H., \& Greef, M. (n.d.). The key features of successful awareness raising campaigns. Retrieved May 27, 2020, from eli-net.eu: http://www.elinet.eu/fileadmin/ELINET/Redaktion/user_upload/The_key_features_of_successful_awareness_ra ising_campaigns_10-15_LM_ELINET.pdf

Mathews, D., Brown, P., Evans, M., \& Hunt, D. (2013). Growth and decay - A guide for teachers (Years 11-12). Calculus: Module 13. In D. Mathews, \& J. Pitkethly (Ed.), Supporting Australian Mathematics Project. Carlton South Vic 3053: Education Services Australia Ltd.

NCDC. (2020, May 23). COVID-19 NIGERIA. (Nigeria Centre for Disease Control (NCDC)) Retrieved May 23, 2020, from ncdc.gov.ng: Https://covid19.ncdc.gov.ng/

NCDC. (2020, May 25). COVID-19 NIGERIA. Retrieved May 25, 2020, from ncdc.gov.ng: https://covid19.ncdc.gov.ng/

NCDC. (2020). Guideline. (Nigeria Centre for Disease Control) Retrieved May 26, 2020, from ncdc.gov.ng: https://covid19.ncdc.gov.ng/guideline/

Odji, E. (2020, May). Roles of Children in the Proliferation of Communicable Diseases in Nigerian Rural Communities: A Designer's Perspective. International Journal of Health and Pharmaceutical Research, 5(3).

Ohadike, D. C. (1991). Diffusion and physiological responses to the influenza pandemic of 1918-19 in Nigeria. Social Science \& Medicine, 32(12), 1393-1399.

Ohia, C., Bakarey, A. S., \& Ahmad, T. (2020). COVID-19 and Nigeria: putting the realities in context. International Journal of Infectious Diseases, 95, 279-281.

Rescher, N. (1998). Fallibilism. Routledge encyclopedia of philosophy, version 1.0., London: Routledge.

Ross, R. (2008). A Concise History of South Africa (Cambridge Concise Histories). Cambridge: Cambridge University Press. https://doi.org/10.1017/CBO9780511805806.

Rourke, A., \& Agencies. (2020, May 25). Americans defy Covid-19 social distancing rules to celebrate Memorial Day holiday. Retrieved May 25, 2020, from theguardian.com: https://www.theguardian.com/world/2020/may/25/americans-defy-covid-19-social-distancingrules-to-celebrate-memorial-day-holiday 
International Journal of Advanced Academic Research | Sciences, Technology and Engineering | ISSN: 2488-9849 Vol. 6, Issue 5 (May 2020)

Journal DOI: 10.46654/ij.24889849 | Article DOI: 10.46654/ij.24889849.e6528

WHO. (2020). Alcohol and COVID-19: what you need to know. Retrieved May 27, 2020, from euro.who.int: http://www.euro.who.int/_data/assets/pdf_file/0010/437608/Alcohol-and-COVID19-what-you-need-to-know.pdf?ua=1

World Bank Group. (2018). Rural population (\% of total population) - Nigeria. Retrieved May 25, 2020, from worldbank.org: https://data.worldbank.org/indicator/SP.RUR.TOTL.ZS?locations=NG

World Population Review. (2020). Population of Cities in Nigeria (2020). Retrieved May 26, 2020, from worldpopulationreview.com: https://worldpopulationreview.com/countries/nigeriapopulation/cities/

Worsnip, A. (2015, May). Possibly False Knowledge. The Journal of Philosophy, 112(5), 225-246. 